\title{
Bluetongue virus: virology, pathogenesis and immunity
}

\author{
Isabelle Schwartz-CorniL ${ }^{1 *}$, Peter P.C. Mertens ${ }^{2}$, Vanessa Contreras ${ }^{1}$, \\ Behzad Hemati ${ }^{1}$, Florentina PASCALE ${ }^{1}$, Emmanuel BRÉARD ${ }^{3}$, \\ Philip S. MELlOR ${ }^{2}$, N. James MaCLaCHLAN ${ }^{4}$, Stéphan Zientara ${ }^{3}$ \\ ${ }^{1}$ Virologie et Immunologie Moléculaires, UR892 INRA, Domaine de Vilvert, \\ 78352 Jouy-en-Josas Cedex, France \\ 2 Department of Arbovirology, Institute for Animal Health, Ash Road, Pirbright, Woking, Surrey, GU24 0NF, UK \\ ${ }^{3}$ UMR 1161 Afssa/INRA/ENVA, 23 Avenue du Général de Gaulle, 94703 Maisons-Alfort, France \\ ${ }^{4}$ Department of Pathology, Microbiology and Immunology, School of Veterinary Medicine, \\ University of California, Davis, CA 95616, USA
}

(Received 24 March 2008; accepted 19 May 2008)

\begin{abstract}
Bluetongue (BT) virus, an orbivirus of the Reoviridae family encompassing 24 known serotypes, is transmitted to ruminants via certain species of biting midges (Culicoides spp.) and causes thrombo-hemorrhagic fevers mainly in sheep. During the 20th century, BTV was endemic in sub-tropical regions but in the last ten years, new strains of BTV (serotypes 1, 2, 4, 8, 9, 16) have appeared in Europe leading to a devastating disease in naive sheep and bovine herds (serotype 8). BTV enters into insect cells via the viral inner core VP7 protein and in mammalian cells via the external capsid VP2 haemagglutinin, which is the major determinant of BTV serotype and neutralization. BTV replicates in mononuclear phagocytes and endothelial cells where it induces expression of inflammatory cytokines as well as apoptosis. BTV can remain as nonreplicating entities concealed in erythrocytes for up to five months. Homologous protection against one BTV serotype involves neutralizing antibodies and T cell responses directed to the external VP2 and VP5 proteins, whereas heterologous protection is supported by T cells directed to the NS1 non structural protein and inner core proteins. Classical inactivated vaccines directed to a specific serotype generate protective immunity and may help control current epidemic situations. New recombinant vaccine strategies that allow differentiating infected from vaccinated animals and that generate cross protective immunity are urgently needed to efficiently combat this worldwide threatening disease.
\end{abstract}

bluetongue / orbivirus / arbovirus / viral haemorrhagic disease / ruminants

Table of Contents

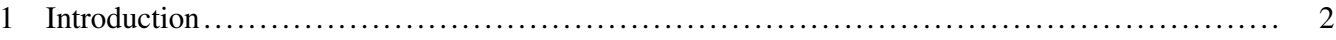

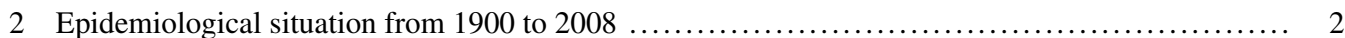

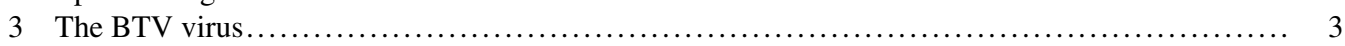

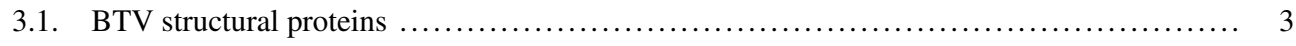

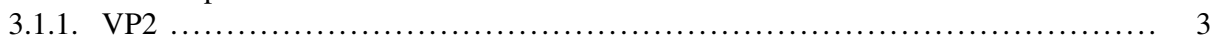

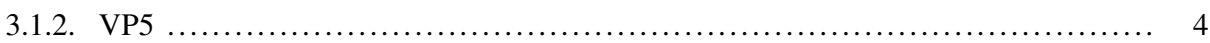

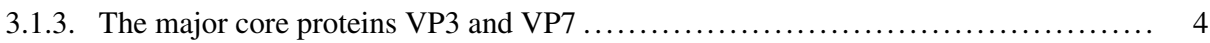

3.1.4. The three minor core proteins VP1, VP4 and VP6 (transcription complex)........... 4

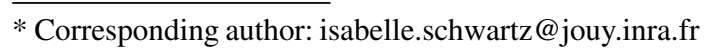


3.2. BTV non structural proteins NS1, NS2, NS3 and NS3A $\ldots \ldots \ldots \ldots \ldots \ldots \ldots \ldots \ldots \ldots \ldots$

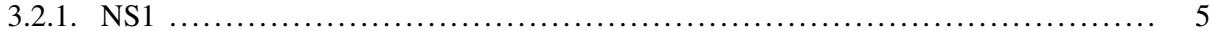

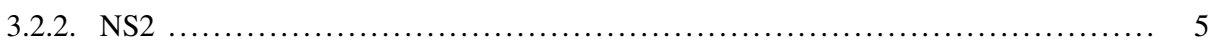

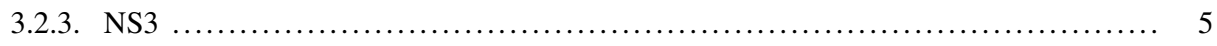

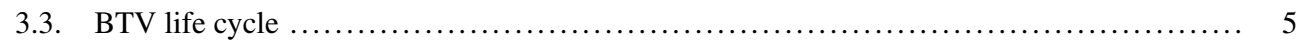

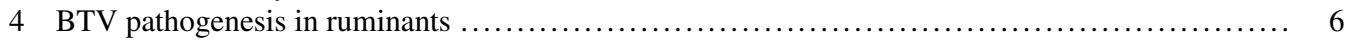

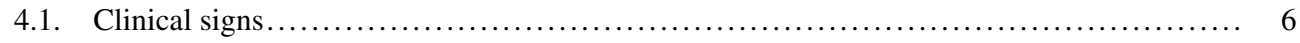

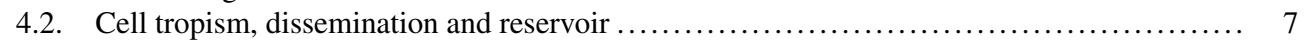

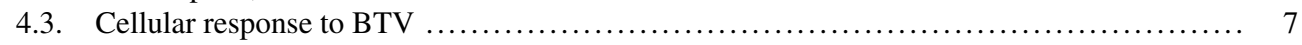

4.3.1. Cell death ......................................................... 7

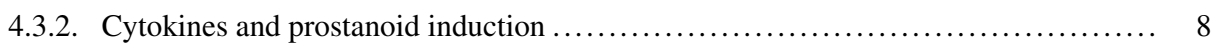

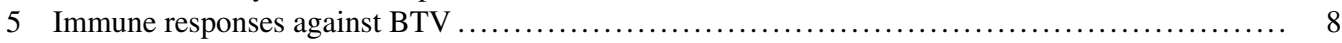

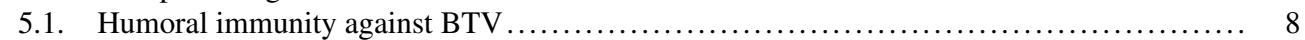

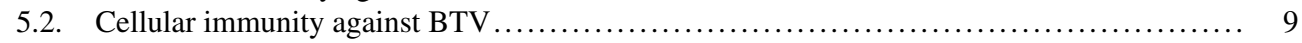

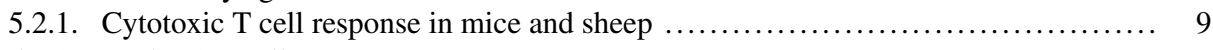

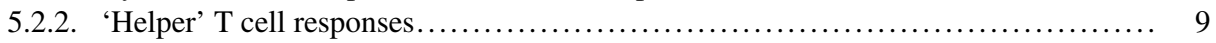

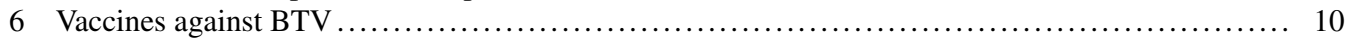

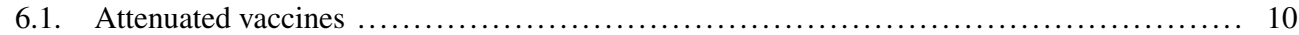

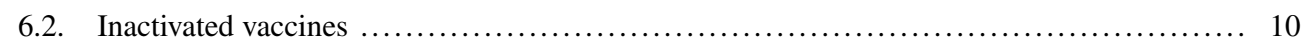

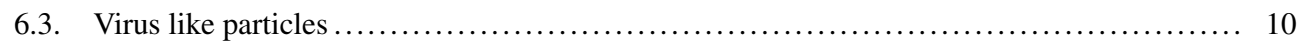

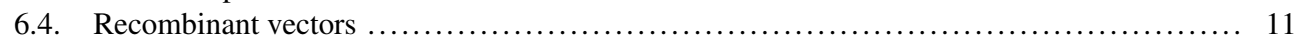

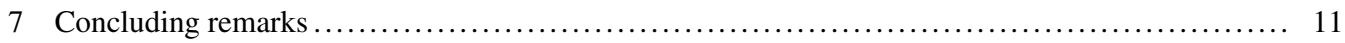

\section{INTRODUCTION}

Bluetongue virus (BTV), an economically important orbivirus of the Reoviridae family, causes a haemorrhagic disease mainly in sheep and occasionally in cattle and some species of deer [70]. BTV is transmitted between its mammalian hosts by certain species of biting midges (Culicoides spp. Diptera: Ceratopogonidae) and it can infect all ruminant species. Although BTV is an arbovirus, it can occasionally be transmitted via seminal fluid and across the placenta [77]. Overall, 24 serotypes have been reported around the world, generating only low levels of cross-protection and complicating vaccination strategies. Due to its economic impact, BT is an Office International des Epizooties (OIE)-listed disease. Economic losses associated with BTV infection are caused directly through reductions in productivity and death and more importantly indirectly through trade losses due to animal movement restrictions, restrictions on the export of cattle semen [3] and the costs of implementing control measures, including diagnostic tests. The recent European outbreaks of BT started in 1998 with the arrival of BTV-9 in Greece. Since then, the epizootic situation regarding BTV in and around Europe has changed dramatically, with incursions of new serotypes into existing endemic zones and the emergence of the virus in previously disease-free areas, affecting immunologically naive herds and generating important economic losses.

\section{EPIDEMIOLOGICAL SITUATION FROM 1900 TO 2008}

BT was first described in an imported Merino sheep in South Africa in the 19th century [72]. In 1902, the disease was mentioned as "a malarial catarrhal fever of sheep" but was named as "bluetongue" in 1905 [72]. During the beginning of the 20th century, BT spread in Africa along with introduction of non indigenous sheep breeds that are highly susceptible to the disease [72]. BTV infection was subsequently recognized as an enzootic disease in areas between latitude $40^{\circ} \mathrm{S}$ and $53^{\circ} \mathrm{N}$ in almost all continents, i.e. America, Africa, Australia and Asia [62], causing worldwide losses that were estimated in 1996 at US\$ 3 billion per year [93]. Prior to 1998, occasional short-lived incursions of BTV 
occurred in southern Europe (Spain, Portugal, Greece and Cyprus [62]). However, since 1998, at least eight distinct BTV strains from six different serotypes (types $1,2,4,8,9,16$ ) have invaded Europe, including many northern European countries (serotype 8) ${ }^{1}[79,85]$.

During August 2006, BTV-8 was detected initially in the Netherlands, before spreading to Germany, Belgium and north-eastern France, generating a total of 2297 northern European BT cases during 2006. After the winter season, the viral infection showed a strong recrudescence and dramatically extended its European distribution in 2007, leading to 40931 cases in total ${ }^{2}$. In France, for instance, the spread of BTV-8 affected 60 departments out of 95 with 15253 reported cases sparing only the southern parts of the country. It also reappeared in 2007 in Belgium (6661 cases), Germany (11 487 cases) and the Netherlands (5798 cases), and it spread to Luxemburg (1315 cases), Denmark (1 case), Switzerland (5 cases), the Czech Republic (1 case) and the UK (65 cases). During 2007, significant numbers of animals infected with BTV-8 were imported into Italy. During January 2008, animals infected with BTV-8 were detected in Spain, and the virus entered Northern Ireland, via importation of infected animals from mainland Europe but it was quickly eliminated by slaughter of all infected and in-contact animals. In 2006, BTV-1 was detected in North Africa and in Sardinia and in 2007, it was found initially in Spain then in the French Pays Basque ${ }^{3}$.

The evolution of BTV infection in Europe is threatening especially when considering the speed and extent of spreading of several serotypes that may favor the emergence of new variants by reassortment [85].

The change of the vector distribution in southern Europe (Culicoides imicola) due

${ }^{1}$ www.reoviridae.org/dsRNA_virus_proteins/ReoID/ BTV-mol-epidem.htm [consulted 28 April 2008]. ${ }^{2} \mathrm{http}: / /$ ec.europa.eu/food/animal/diseases/adns/index _en.htm [consulted 28 April 2008].

${ }^{\overline{3}} \mathrm{http} / / /$ ec.europa.eu/food/animal/diseases/control measures/index_en.htm. [consulted 20 March 2008]. to climate change may partially explain the extension of the bluetongue virus distribution to new geographical areas, such as to Corsica (France) [79, 85]. However, C. imicola has not been found in northern Europe where BTV-8 was transmitted very efficiently, nor in the Balkan areas of Europe where BTV-9 occurred. Novel vector species of Culicoides, belonging to the $C$. obsoletus and $C$. pulicaris complexes of species, are probably involved in BTV transmission in such areas [63].

The recent detection of eight additional BTV serotypes in the USA strongly suggests that the changes in BT distribution first detected in Europe may be a worldwide phenomenon, perhaps as a consequence of climate change ${ }^{4}[50]$.

\section{THE BTV VIRUS}

Bluetongue virus (density $1.337 \mathrm{~g} / \mathrm{cm}^{3}$ [65]) is a non enveloped virus with a genome of approximately 19200 base pairs composed of ten linear segments of double-stranded RNA (dsRNA), containing $57 \% \mathrm{AU}$ and $43 \% \mathrm{GC}$, with conserved $5^{\prime}$ and $3^{\prime}$ terminal sequences (GUUAAA at $5^{\prime}$, and ACUUAC at $3^{\prime}$ ends of the positive strand [64]). The 10 dsRNA segments are packaged within a triple layered icosahedral protein capsid (approximately $90 \mathrm{~nm}$ in diameter) [31, 39, 74]. The virus particle has been extensively studied at high resolution by cryo-electro-microscopy and $\mathrm{X}$-ray crystallography techniques [31, 74]. The outer shell is composed of two structural proteins, 60 trimers of VP2 $(111 \mathrm{kDa})$ and 120 trimers of VP5 $(59 \mathrm{kDa})$. The intermediate layer consists of the major immunodominant VP7 structural protein $(38 \mathrm{kDa})$, organized in 260 trimers forming a $T=13$ icosahedral lattice covering the subcore [74, 82]. The subcore consists of the 12 decamers of the VP3 protein $(100 \mathrm{kDa})$, one centered on each of the five fold axes of the icosahedral particle structure [31]. The 120 molecules of

\footnotetext{
${ }^{4}$ Johnson D., Identification of new United States bluetongue virus types, Proc. Annu Meet. US Anim. Health Assoc. (2007) in press.
} 
VP3 can be considered as a 'pseudo $\mathrm{T}=2$ ' icosaedral lattice, which houses the viral genome segments and three minor proteins involved in transcription and replication, namely the RNA-dependent RNA polymerase (VP1, $149 \mathrm{kDa}$ ), the RNA capping enzyme (VP4, $76 \mathrm{kDa}$ ) and the dsRNA helicase (VP6, $36 \mathrm{kDa}$ ) [74]. VP7 forms the outer layer of the transcriptionally active virus 'core' [65]. Non-structural proteins (NS1, NS2, NS3 and NS3A) probably participate in the control of BTV replication, maturation and export from the infected cell. Unlike most single stranded RNA (ssRNA) viruses, the orbiviruses are genetically and antigenically stable throughout infection; point mutations do not appear to arise in vivo, at least at the high frequency noted with many non-segmented ssRNA viruses [16].

\subsection{BTV structural proteins (Fig. 1)}

\subsubsection{VP2}

The trimers of the VP2 form 'triskelion' motifs (three interlocked spirals) on the outer layer [31]. VP2 is responsible for receptor binding, hemagglutination and eliciting serotype-specific neutralizing antibodies [35, 82]. Recombinant VP2 has a strong affinity for glycophorin A, a sialoglycoprotein component of erythrocytes, an interaction that could be involved in BTV binding to erythrocytes [35]. Furthermore, VP2 and glycophorin can inhibit BTV attachment to susceptible cells, suggesting that the BTV receptor involves VP2 interaction with a cell surface glycoprotein [35]. Inside the cell, VP2 associates to vimentin, which allows the proper sub-cellular localization of the protein and the interaction of mature BTV particles to intermediate filaments [8]. Disruption of the VP2/vimentin interaction by pharmacological inhibitors leads to blockade of the virus egress [8].

VP2 is the major determinant of BTV serotype, with a minor role for VP5 [66]. Phylogenetic comparisons of VP2 from the 24 reference strains [58] show a perfect correlation between sequence variation in genome segment 2 (Seg-2), coding for VP2, and BTV serotype. Sequences of seg-2

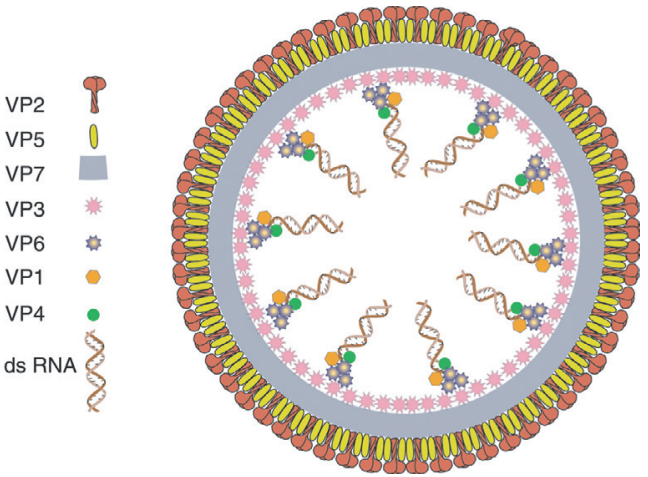

Figure 1. Representative scheme of BTV structural proteins and dsRNA segments. (A colour version of this figure is available at www.edpsciences.org.)

from the 24 BTV types cluster as ten distinct evolutionary lineages, identified as nucleotypes A-J. The inter-serotype VP2 nucleotide sequences varied from $29 \%$ (BTV-8 and BTV-18) to $59 \%$ (BTV-16 and BTV-22). Sequencing and phylogenetic comparisons of VP2 also revealed significant variations between strains of the same serotype that were derived from different geographical areas, with a maximum of $30 \%$ nucleotide sequence variation [58] within the same serotype. These geographical variations define eastern and western VP2 topotypes within individual serotypes. Oligonucleotide primers can be designed targeting Seg-2, that can be used in RT-PCR assays to facilitate typing of BTV field and vaccine isolates of each serotype and topotype [69]. Despite the overall sequence variability, some features of VP2 appeared to be conserved across serotypes, including the hydrophobicity profile, charge distribution and the position of certain cysteine residues [58].

\subsubsection{VP5}

In contrast to VP2, VP5 is significantly more conserved but shows some degree of variations that reflects the geographic origin [88]. Trimers of VP5 form the globular motifs of the outer layer of the BTV virus particle [74]. VP5 has recently been shown to be a membrane penetration protein that mediates release of viral particles from endosomal compartments into the cytoplasm [34]. Analysis 
of the VP5 sequence using secondary structure prediction algorithms indicates that this protein is predominantly $\boldsymbol{\alpha}$-helical, with an amphipathic helical domain at the $\mathrm{N}$ terminus followed by a coiled coil domain, thus sharing structural features with class I fusion proteins of enveloped viruses [74]. Furthermore, VP5 undergoes $\mathrm{pH}$-dependent conformational changes that allow membrane fusion and syncytium formation [25]. The syncytium formation by VP5 is inhibited in the presence of VP2 when expressed in a membrane-anchored form.

\subsubsection{The major core proteins VP3 and VP7}

VP3 and to a lesser extent VP7 [102] are conserved proteins and are hydrophobic in nature. They play an important role in the structural integrity of the virus core. They express group-specific antigenic determinants defining several distinct phylogenetic groups [4].

Importantly, cores are poorly infectious or even non-infectious in different mammalian cells but they are at least 100 fold more infectious for adult Culicoides midges or a Culicoides cell line (KC cells) [61, 67]. VP7 can mediate attachment and penetration of insect cells in the absence of either VP2 or VP5, a process that may involve an arginine-glycine-aspartate (RGD) tripeptide motif present at amino acid residues 168 to 170 on the outermost surface of the VP7 trimers on the BTV core [97]. VP7 can bind to glycosaminoglycans, although it appears likely that other specific receptors are also involved in cell attachment and penetration.

The VP3/VP7 complex protects the viral dsRNA genome from intracellular surveillance, thus preventing activation of type I interferon (IFN) production via cytoplasmic sensors such as cytosolic helicases, or interactions with dicer and RNA silencing mechanisms.

\subsubsection{The three minor core proteins VP1, VP4 and VP6 (transcription complex)}

VP1 is present in a low molar ratio (approximately 12 copies per particle) within the virion [41, 91]. VP1 can extend RNA synthesis from oligo(A) primers and acts as the BTV replicase that synthesizes dsRNA from a viral plus-strand RNA template [11]. VP1 has an optimal activity at $27^{\circ} \mathrm{C}$ to $37^{\circ} \mathrm{C}$, allowing efficient replication in both insect and mammalian cells.

The early BTV mRNA are capped. The cap (methylguanosine connected to the first nucleoside) stabilizes the mRNA and allows efficient translation. In cells, capping requires the action of four distinct enzymes. In BTV, all four reactions are catalyzed by the single VP4 protein, whose crystal structure shows an elongated modular architecture that provides a scaffold for an assemblage of active sites [92].

The VP6 protein has ATP binding activity and displays RNA-dependent ATPase and helicase functions. It unwinds duplexes of dsRNA and could assist mRNA synthesis from the genomic dsRNA template [89].

\subsection{BTV non structural proteins NS1, NS2, NS3 and NS3A}

The two larger BTV non structural proteins, NS1 and NS2, are the first and second most highly expressed proteins in infected cells [41], whereas the two closely related minor proteins NS3 and NS3A are barely detectable in mammalian cells. However, NS3 and NS3a are synthesised in much larger amounts in insect cells, suggesting that their role may be primarily related to BTV replication and dissemination within the insect vector [32].

\subsection{1. $N S 1$}

Electron microscopic analysis of thin sections of BTV-infected cells have revealed a large number of virus-specific tubules $(52.3 \mathrm{~nm}$ diameter and $1000 \mathrm{~nm}$ long) composed of multimers of the NS1 protein, a striking intracellular morphological feature of BTV infection. Expression of an $\mathrm{scFv}$ to NS1 reduced the cytopathic effects of BTV, suggesting that NS1 has a role in BTV cytopathogenesis [75]. In addition, recombinant NS1 expressed in insect cells, which is 
highly immunogenic and easy to purify, has been used as a scaffold for exogenous peptides to generate heterologous recombinant protein vaccines against foot and mouth disease and influenza [29] and HIV [55].

\subsubsection{NS2}

NS2 is the major constituent of the viral inclusion bodies (VIB) seen in infected cells mainly in the vicinity of the nucleus. NS2 binds to viral ssRNA [105] and hydrolyses nucleotide triphosphates to nucleotide monophosphates [37]. These two properties imply that NS2 might be involved in some way in selection and condensation of the BTV ssRNA segments prior to genome encapsidation. NS2 expression in cells is sufficient for formation of inclusion bodies and it recruits VP3, suggesting that NS2 is a key player in virus replication and core assembly [53].

\subsubsection{NS3}

NS3 and its shorter form, NS3A, which lacks the N-terminal 13 amino acids of NS3, are the only membrane proteins encoded by orbiviruses. Interestingly, NS3 and NS3A appear to be associated with smooth intracellular membranes, although they are also present at the plasma membrane. NS3 functions as a viroporin, facilitating virus release by inducing membrane permeabilization [33]. In addition, NS3 binds to the cellular protein Tsg101 [104], allowing BTV particles to also leave host cells by a budding mechanism, similarly to retroviruses. This budding mechanism might be involved in BTV egress from insect cells in which BTV does not induce significant cytopathic effect, whereas the viroporin mechanism would be more prominent in mammalian cells.

\subsection{BTV life cycle}

BTV interacts with the target cell surface via VP2 trimers binding to cell surface glycoproteins and possibly to other receptors. BTV core particles can also bind to cells (particularly insect cells) via VP7 trimers. The BTV particle is then internalized in endosomes via a clathrin-dependent endocytosis pathway [26]. VP2 dissociates from the outer capsid layer in early endosomes. Acidification induces VP5 fusion with the endosomal membrane [25], delivering the transcriptionally active core into the cell cytoplasm. Like other members of the Reoviridae family, BTV replicates within the cytoplasm of infected cells. Within the BTV core, the VP1 molecules transcribe positive sense ssRNA copies from each of the ten BTV genome segments [11]. These mRNA molecules are capped by the guanylyl-transferase and transmethylase activities of VP4 [92] and leave the particles via channels situated at the five fold axes of the core particle [68]. The viral mRNA serve as templates for translation in viral proteins, starting within two hours post infection [20]. Viral positive RNA are directed to VIB where the correct encapsidation of the different segments (nature and numbers) within the VP3 shell may involve interactions with the helicase VP6 [89], the ssRNA binding NS2 protein [53], and the VP1 and VP4 proteins. VP1 then synthesizes the negative strand RNA to produce dsRNA [11]. It has been proposed that each dsRNA segment independently associates with a different transcription complex (VP1, VP4 and VP6) located at the inner side of VP3 along a five fold axis, making a 'flower shape' in cryoelectromicroscopy [74].

Exchanges of dsRNA segments can occur when two different BTV (serotypes or strains) infect the same cells, contributing to the evolution of BTV through the process of reassortment. The process of reassortment may involve fusion of VIB formed with different viral particles. For unknown reasons, some segments are more often exchanged than others [30].

The VP3 subcores are relatively fragile and unstable structures [82] that serve as a scaffold for the addition of VP7 trimers, giving rise to more rigid and stable cores. The outer capsid proteins VP2 and VP5 appear to be added to the progeny core particle surface at the periphery of the VIB as they enter the host cell cytoplasm. Mature progeny virus particles are transported within 
the cytoplasm on microtubules involving VP2/vimentin interactions [8]. Release of virions from the infected cell occurs via cell membrane destabilization mediated by the NS3 viroporin activity [33], in some cases via budding, or as a result of cell death and lysis. Production of mature particles is exponential during the 8 th and 24th hours post infection.

\section{BTV PATHOGENESIS IN RUMINANTS}

\subsection{Clinical signs}

In temperate climates in enzootic zones, outbreaks of BTV occur seasonally in association with high populations of the adult Culicoides vectors and can affect domestic and wild ruminants [7, 93]. Cattle, which are susceptible to BTV infection usually do not develop overt clinical signs, but they can manifest an IgE-mediated hypersensitivity reaction [1]. However, cattle are important in transmission, acting as reservoirs for the virus [1]. The strain of BTV serotype 8 that has invaded northern Europe is unusual because a large number of infected cattle also developed clinical signs [22]. Sheep and some wild ruminants display a variety of clinical manifestations, ranging from subclinical infections or mild disease, to acute or even fatal disease. Viraemia is usually detectable around 3-5 days post infection in sheep [27]. Clinical signs include pyrexia, tachypnoea and lethargy. Gross pathological alterations are characterized by widespread oedema, haemorrhages especially in the lymph nodes, lungs, heart and skeletal muscles and/or necrosis of the mucosal surfaces in the oro-nasal and alimentary systems [12]. Lungs, the shock organ in ruminants [71], are especially susceptible to permeability disorders of the vasculature induced by BTV. Microscopic lesions include endothelial hypertrophy, vascular stasis and thrombosis with tissue infarction. Animals that survive acute infection may develop chronic dermatitis, and vesicular and erosive lesions at interdigital and mucosal surfaces [13]. A panleukopenia reaches its maximum at day seven to eight post infection and affects all lymphocytes, especially CD8 T cells [23].
The severity of the disease induced by BTV varies with host age and health status [76]. Immunodeficiency due to concurrent infections can strongly exacerbate disease manifestations [13], as well as exposure to strong solar radiations.

\subsection{Cell tropism, dissemination and reservoir}

After initial replication in the lymph nodes draining the sites of inoculation, BTV disseminates to secondary sites, principally the lungs and spleen, where it replicates in endothelium and mononuclear phagocytes [6]. BTV can disseminate via lymph [6] or/and via blood [13]. BTV infects monocytes both in vivo and in vitro. In vivo, infectious BTV can be retrieved transiently ( $<1$ week) from monocytes (minimum $10^{5}$ cells) [13, 100]. Monocytes also express BTV antigens in vivo at low frequency (four NS2 antigen-positive monocytes per $2 \times 10^{5}$ peripheral blood mononuclear cells [100]). In vitro, around $15 \%$ of monocytes express BTV VP7 after $36 \mathrm{~h}$ in culture [5] and they produce low amounts of infectious BTV in vitro [100]. Conversely, resting $\mathrm{T}$ lymphocytes are not efficient at supporting BTV replication [100] unless they are activated by mitogens [5]. Interestingly, $\gamma \delta$ $\mathrm{T}$ cell lines can be productively infected in vitro [96] and blood $\gamma \delta$ T cells from infected sheep (3-13 days post infection) have been induced to produce infectious BTV when cocultivated with skin fibroblasts [96]. However, it is unclear how monocytes and possibly blast $\mathrm{T}$ cells are involved in vivo in the pathogenesis of BTV. Last but not least, infectious BTV can also be detected in the intracellular vesicles of erythrocytes, in which it does not replicate but persists in invaginations of cell membrane [60, 100]. The association of infectious BTV with erythrocytes is detected very early after infection (24 h) [13] and persists throughout viraemia $[60,87]$.

Consequently, BTV infection in ruminants is characterized by a prolonged cell-associated viraemia that can persist in the presence of high titres of neutralizing antibody, although recovered animals are immune to re-infection with the homologous serotype of BTV. In sheep and cattle, infectious BTV can be

(page number not for citation purpose) Page 7 of 16 
detected in the blood for 35 to 60 days [6] and viral structures for up to 160 days [54]. It has been proposed that particles associated with erythrocytes are protected from early immune clearance. Furthermore, detection of BTV RNA up to 145 days after infection is remarkably similar to the lifespan of the ruminant erythrocytes, suggesting that erythrocytes are likely to be the critical mechanism that allows cattle to serve as natural reservoir hosts of BTV [12]. Some other work indicated that BTV RNA can be detected even up to 222 days [9].

In enzootic areas, BT usually appears in late autumn after long periods of quiescence (8-12 months), a phenomenon called overwintering [96]. However, conventional models for the transmission of BTV suggest that if adverse winter conditions last for more than 100 days, the virus should be unable to survive from one year to the next. Persistence of BTV in the larvae of vector Culicoides is considered to be highly improbable [61] although it cannot be ruled out [101]. Some authors have postulated that persistently infected $\gamma \delta \mathrm{T}$ cells, recruited by midge biting, could facilitate the transmission of BTV for periods as long as nine weeks post infection in Dorset sheep [96]. However, this finding was not confirmed in another study using a different sheep breed (Merino sheep) [57].

\subsection{Cellular response to BTV}

Viral haemorrhagic diseases are not only a consequence of direct viral damage to the cells but also the result of intense and sometimes deregulated inflammatory processes. BTV reduces endothelial electrical resistance in vitro associated to p38 MAP kinase-dependent cytoskeletal rearrangements [14]. In addition, BTV infections induce cell death in many cell types and an important inflammatory cell response.

\subsubsection{Cell death}

In mammalian cells, BTV induces cell death (apoptosis and/or necrosis) in cell lines [73], microvascular ovine and bovine endothelial cells [18], monocytes [5] and in WC1-activated $\gamma \delta \mathrm{T}$ cells [96]. In mammalian cell lines, uncoating of BTV, but not BTV replication, is required to trigger apoptosis [73]. Extracellular treatment with a combination of the viral outer capsid proteins VP2 and VP5, and the cell penetration protein VP5 is sufficient to trigger apoptosis, involving activation of NF- $\kappa \mathrm{B}$ [73]. However, some cell types that support the replication of the virus do not demonstrate a cytopathic effect to BTV, such as insect cells [73], $\gamma \delta \mathrm{T}$ cell lines [96] and activated blood lymphocytes [5]. The budding versus the viroporin-mediated viral exit mechanism might partially explain this difference [104].

\subsubsection{Cytokines and prostanoid induction}

Infection of bovine and ovine microvascular endothelial cells induces the transcription of interleukin 1 (IL-1), IL-8, IL-6, cyclooxygenase-2, and inducible nitric oxide synthase [19]. These mediators have been involved in the pathogenesis of severe viral haemorragic fevers. Infection of sheep and cattle with BTV induces a plasmatic increase of prostacyclin and thromboxane [19]. Thromboxane is a strong pro-coagulant factor whereas prostacyclin is a potent vasodilatator and inhibitor of platelet aggregation. There is a much higher prostacyclin/thromboxane ratio in cattle, which may explain the lower sensitivity of cattle to BTV induced microvascular injury and thrombosis [19].

BTV is also a strong inducer of type I IFN in vivo, in sheep [27], cattle [59] and mice [43]. A strain of BTV serotype 8 was shown to be an extremely potent inducer in vivo in mice, even when UV-irradiated [43]. Strains of many BTV serotypes have been reported as IFN inducers but they may differ in their ability to induce IFN depending on the cell context [28]. A wide variety of cells produce type I IFN after BTV stimulation in vitro, including mouse embryo cells [38], human leucocytes [42], leucocytes from adult sheep [80]. Double stranded RNA from BTV also induced IFN in mice [21]. However, 
the exact viral component involved in the induction is unknown.

\section{IMMUNE RESPONSES AGAINST BTV}

Transfer of antibodies [48] and T cells [49] in monozygotic sheep have shown that both humoral and cellular immune effector mechanisms are able to protect sheep against BTV infection and disease.

\subsection{Humoral immunity against BTV}

Passive serum transfer studies have shown that BTV specific antibodies can confer protection in a serotype specific manner, suggesting an in vivo role for antibody-mediated viral neutralization [48]. However, exactly how antibodies interfere with BTV infection in vivo is unknown. Attempts to demonstrate the existence of antibody-dependent cell-mediated cytotoxicity (ADCC) and complement-facilitated antibody-dependent cell-mediated cytotoxicity in both cattle and sheep, using a variety of systems, have consistently failed [47].

VP2 and VP5 are the only BTV proteins shown to induce neutralizing antibodies $[56,81]$ with VP2 being the major protein involved in serotype specificity (see above and $[39,66])$. Sheep inoculated with VP2, either isolated from intact particles or generated by in vitro expression, produced virusneutralizing antibodies and were resistant to challenge with the homologous BTV serotype $[40,81]$. Two hydrophylic domains in VP2, AA 199-213 (region 1) and AA 321-346 (region 2), contain multiple conformation-dependent neutralization epitopes [17]. Mutations in neutralization escape mutants clustered in these two regions [17], where the lowest level of AA identity between serotypes was also found [58]. Interestingly mutations in the region 1 of the VP2 protein of the same original BTV serotype 17 generated two co-circulating strains that displayed distinct neutralization characteristics [103].

Co-expression of VP2 with VP5, or in combination with core proteins to form double-shelled virus-like particles, enhanced the neutralizing antibody response of inoculated sheep as compared to VP2 alone [56, $81,83,84]$. VP5 improved the neutralization of BTV, possibly through its conformational influence on VP2 $[15,66]$. In addition VP5 may directly induce neutralizing antibodies [56] although neutralizing monoclonal antibodies to VP5 have not been described.

Neutralizing antibodies generally protect only against homologous virus, although serial infections of sheep with two serotypes can protect the animals against challenge with a third serotype [46]. Depending on serotypes, the antibodies can protect against the infection by a limited number of other serotypes, associated to similarities of sequences in VP2 [58]. Since the level of neutralizing antibodies elicited by VP2 greatly varies between sheep [81], an outbred species, vaccine strategies would benefit from inclusion of both VP2 and VP5 antigens.

\subsection{Cellular immunity against BTV}

The level of neutralizing antibodies does not always correlate with the degree of protection after vaccination with live BTV [48] and some inactivated vaccine preparations can confer protection in the absence of detectable levels of neutralizing antibodies [90]. Furthermore adoptive transfer of BTV-specific cytotoxic T lymphocytes (CTL) to monozygotic sheep has been shown to confer partial protection [48, 49], indicating that CTL participate in protection.

\subsubsection{Cytotoxic T cell response in mice and sheep}

Evidence that the cross-protective immune response to BTV involves CTL has been obtained both in laboratory mouse models $[45,51]$ and sheep $[49,94]$.

In mice, statistical analysis of the CTL response indicated that non structural protein peptides are the predominant source of homotypic and heterotypic CTL recognition, followed by the minor core inner capsid protein VP3 and finally the inner capsid protein VP7 and the outer capsid proteins VP2 and VP5 [51]. The outer capsid proteins VP2 and 
VP5 that vary considerably between serotypes were not recognized by heterotypic CTL [51]. Furthermore, Baculovirus expressed NS2, NS1, NS3, VP1, V4 and VP6 induced a CTL response in mice, which was partially protective against a vaccinia virus expressing the homologous protein only in the case of NS2 [52].

In sheep, BTV-specific cross-reactive CTL have been described [49] and CTL lines have been shown to inhibit viral replication in skin fibroblasts infected with homologous and heterologous virus types [94]. Recombinant vaccinia viruses expressing BTV antigens demonstrated that VP2 and NS1 are major CTL immunogens and that NS1-specific, but not VP2-specific CTL are cross-reactive [2]. Furthermore, the non-structural protein NS1 was recognized by CTL from all Merino sheep immunized with recombinant vaccinia viruses, while VP2, VP3, VP5 and VP7 were recognized by CTL from only some sheep [44]. The other proteins (NS2, NS3, VP4, VP6) did not appear to contain CTL epitopes, whereas NS2 induced CTL in mice [52]. Thus, important variations in the protein targets of CTL exist between individuals and host species.

\subsection{2. 'Helper' $T$ cell responses}

Major 'helper' serotype-specific determinants are present in VP2 and some in VP5, while major serotype cross-reactive determinants are located within the core structural proteins [95]. When sheep were vaccinated with a capripox virus encoding for VP7, clinical protection was obtained against heterotypic challenge, although the virus still replicated [99]. The immune effectors involved in the VP7 induced protection were probably CD4 T cells, but their direct functional contribution was not evaluated. Besides, VP7 is immunodominant during antibody production using in vitro priming techniques, but the antibodies are not neutralizing and probably not protective ${ }^{5}$.

$\overline{{ }^{5} \text { Collen T., Mertens P.P., Burroughs J.N., Butcher }}$ R.N., Anderson J., Windsor M., Takamatsu H., Monoclonal antibodies produced against blue-

\section{VACCINES AGAINST BTV}

Much effort has been devoted to the development of vaccines against BT. The protective vaccines against BT in ruminants that are currently available commercially can be either attenuated or inactivated. Their protective activity is serotype-specific, probably due to the key role of the outer protein VP2 in the $\mathrm{B}$ and $\mathrm{T}$ cell mediated protective immunity. Thus, in endemic areas where multiple BTV serotypes may be present, efficient vaccines against several serotypes may be necessary. Furthermore, vaccines against BT need to be safe and should allow differentiating between vaccinated and infected animals (DIVA vaccines), in order to facilitate trade. Due to these three requirements (multi-serotypes, safety and DIVA properties), vaccination against BTV can be a difficult and controversial issue. Below, we summarize the findings of a recent review [86] on the pros and cons of inactivated and attenuated vaccines.

\subsection{Attenuated vaccines}

Attenuated vaccines produced by Onderstepoort Biological Products (South Africa) have long been used to control BT in sheep in southern Africa, and more recently in Corsica, the Balearic Islands and Italy. These vaccines provide robust protection after one injection for at least one year and they are cheap to produce [86]. However, these vaccines are not always safe, especially in some susceptible breeds [98]. Indeed their attenuation is difficult to control. They can generate mild clinical signs after injection, abortions, transiently depressed milk production and decreased semen quality [86]. Moreover, as the vaccine virus can elicit a viraemia of over two weeks in vaccinated sheep [98], they can be spread to vectors with the potential for reversion to

tongue and African horse sickness viruses by in vitro immunization show a bias for structural protein VP7, In: Walton T.E., Osburn B.I. (Eds.), Bluetongue, African Horse Sickness and related Orbivirus, Proceedings of the 2nd International Symposium, CRC Press, Boca Raton, FL, USA, 1992, pp. 416-422. 
virulence and/or reassortment with genes of the wild-type virus giving rise to novel BTV strains with modified virulence [86]. Finally, attenuated vaccines are not DIVA vaccines. For all these reasons, other vaccine strategies are required.

\subsection{Inactivated vaccines}

Inactivated vaccines can generate a safe and protective immunity if properly prepared [86]. However, a single vaccination may induce only the transient detection of neutralizing antibodies and it is usually insufficient to provide an immunity that lasts for several months (particularly in cattle). Nonetheless, a strong and long-term immunity can be elicited by two injections [86]. DIVA inactivated BT vaccines are theoretically possible but have not yet been developed. Although inactivated vaccines are expensive to produce and their use is constraining, they are the best currently available safety/efficacy compromise. The European Food Safety Authority has recommended that countries use killed vaccines [24] and they have been used since 2005 in some European countries (including France and Italy) [86]. However, the available inactivated vaccines are directed to only few serotypes.

\subsection{Virus like particles}

BTV structural proteins can be produced as recombinant proteins encoded by Baculoviruses in insect cells, in which they auto-assemble as virus like particles (VLP), presenting BTV antigenicity without BTV genetic information [83]. They are thus considered to be naturally safe and they do not require any process of inactivation, although a recent study pointed out that laboratory-produced VLP batches included large quantities of Baculoviruses [36]. Clinical batches should be carefully checked for the presence of Baculovirus and the potential risk of their replication in insect vectors in the field. Regardless, VLP are promising vaccine tools with which to generate multivalent BT vaccines, since VP2 from several viral strains can be included [84]. VLP have been shown to be efficacious in protecting against homologous BTV challenge and partially protecting against heterologous BTV challenge in laboratory trials $[83,84]$. Further studies are awaited to evaluate their structural long-term stability, their cost of production/purification and their efficacy in the field.

\subsection{Recombinant vectors}

Recombinant vectors could be developed as future vaccines, if they are safe, inexpensive, DIVA, flexible for multi-serotype inclusions and if they provide long-term protective immunity in one shot. Although the road is still long to achieve these goals, some preliminary and promising laboratory studies have been published using poxvirus-derived vectors. Indeed, initial work showed that co-injection of vaccinia virus encoding for VP2 and VP5 proteins (three injections, 21 days apart) could confer protective immunity in sheep [56]. More recently, a canarypoxbased vector that expressed optimized synthetic genes for VP2 and VP5 (two injections, 22 days apart) elicited high levels of neutralizing antibodies, a differential reactivity to VP7 as compared to sera from infected sheep (DIVA), and strong protection against homologous challenge (BTV-17); such a non replicative canarypox vector is extensively and safely used over the world in other recombinant vaccines [10]. Finally, a replicative capripox encoding for VP2, VP7, NS1 and NS3 (one injection) was partially protective in sheep [78, 99]. Thus, recombinant vectors can provide protective immunity with DIVA properties but their efficacy barely reaches that of inactivated vaccines, still requiring several injections for efficient long-term protection. Recombinant vectors providing high levels of exogenous protein synthesis and generating a strong anamnestic cross protective immunity are awaited to be qualified for a reasonable development for field applications.

\section{CONCLUDING REMARKS}

The worrying epidemiological map of BTV infections in Europe illustrates the risk to the 
entire world of emerging microbial diseases that were previously confined to specific geographic areas, spreading due to global warming and increased trade. It also reveals that many questions remain regarding the physiopathological mechanisms of the BTV induced thrombo-haemorrhagic disease, the species/ breeds/individual genetic bases of sensitivity to BT disease, the molecular basis of BTV virulence, the insect and mammalian reservoirs, and the immune effectors involved in cross protective immunity. Although classical vaccination theoretically can control $\mathrm{BT}$, major economical constraints may prevent its effectiveness, due to the huge vaccine supplies necessary to insure a $>80 \%$ coverage in ruminants, the costs inherent in the use of inactivated vaccines, the lack of cross serotype protection in face of possible new serotype invasions and the different policies applied in neighboring countries.

Acknowledgements. The authors are grateful to Marc Weber (INRA, Jouy-en-Josas, France) who drew Figure 1.

\section{REFERENCES}

[1] Anderson G.A., Stott J.L., Gershwin L.J., Osburn B.I., Identification of bluetongue virus-specific immunoglobulin E in cattle, J. Gen. Virol. (1987) 68:2509-2514.

[2] Andrew M., Whiteley P., Janardhana V., Lobato Z., Gould A., Coupar B., Antigen specificity of the ovine cytotoxic $\mathrm{T}$ lymphocyte response to bluetongue virus, Vet. Immunol. Immunopathol. (1995) 47:311-322.

[3] Anonymous, Commission regulation (EC) No 1266/2007 of 26 October 2007 on implementing rules for Council Directive 2000/75/EC as regards the control, monitoring, surveillance and restrictions on movements of certain animals of susceptible species in relation to bluetongue, Official Journal of the European Union L 283, 27.10.2007, pp. 37-52.

[4] Anthony S., Jones H., Darpel K.E., Elliott H., Maan S., Samuel A., et al., A duplex RT-PCR assay for detection of genome segment 7 (VP7 gene) from 24 BTV serotypes, J. Virol. Methods (2007) 141:188197.

[5] Barratt-Boyes S.M., Rossitto P.V., Stott J.L., MacLachlan N.J., Flow cytometric analysis of in vitro bluetongue virus infection of bovine blood mononuclear cells, J. Gen. Virol. (1992) 73:19531960.

[6] Barratt-Boyes S.M., MacLachlan N.J., Dynamics of viral spread in bluetongue virus infected calves, Vet. Microbiol. (1994) 40:361-371.

[7] Barratt-Boyes S.M., MacLachlan N.J., Pathogenesis of bluetongue virus infection of cattle, J. Am. Vet. Med. Assoc. (1995) 206:1322-1329.

[8] Bhattacharya B., Noad R.J., Roy P., Interaction between bluetongue virus outer capsid protein VP2 and vimentin is necessary for virus egress, Virol. J. (2007) 4:7.

[9] Bonneau K.R., DeMaula C.D., Mullens B.A., MacLachlan N.J., Duration of viraemia infectious to Culicoides sonorensis in bluetongue virus-infected cattle and sheep, Vet. Microbiol. (2002) 88:115-125.

[10] Boone J.D., Balasuriya U.B., Karaca K., Audonnet J.C., Yao J., He L., et al., Recombinant canarypox virus vaccine co-expressing genes encoding the VP2 and VP5 outer capsid proteins of bluetongue virus induces high level protection in sheep, Vaccine (2007) 25:672-678.

[11] Boyce M., Wehrfritz J., Noad R., Roy P., Purified recombinant bluetongue virus VP1 exhibits RNA replicase activity, J. Virol. (2004) 78:3994-4002.

[12] Brewer A.W., MacLachlan N.J., The pathogenesis of bluetongue virus infection of bovine blood cells in vitro: ultrastructural characterization, Arch. Virol. (1994) 136:287-298.

[13] Brodie S.J., Wilson W.C., O'Hearn P.M., Muthui D., Diem K., Pearson L.D., The effects of pharmacological and lentivirus-induced immune suppression on orbivirus pathogenesis: assessment of virus burden in blood monocytes and tissues by reverse transcriptionin situ PCR, J. Virol. (1998) 72:5599-5609.

[14] Chiang E.T., Persaud-Sawin D.A., Kulkarni S., Garcia J.G., Imani F., Bluetongue virus and doublestranded RNA increase human vascular permeability: role of p38 MAPK, J. Clin. Immunol. (2006) 26: 406-416.

[15] Cowley J.A., Gorman B.M., Cross-neutralization of genetic reassortants of bluetongue virus serotypes 20 and 21, Vet. Microbiol. (1989) 19:37-51.

[16] De Mattos C.C., de Mattos C.A., Osburn B.I., MacLachlan N.J., Evolution of the L2 gene of strains of bluetongue virus serotype 10 isolated in California, Virology (1994) 201:173-177.

[17] DeMaula C.D., Bonneau K.R., MacLachlan N.J., Changes in the outer capsid proteins of bluetongue virus serotype ten that abrogate neutralization by monoclonal antibodies, Virus Res. (2000) 67:59-66. 
[18] DeMaula C.D., Jutila M.A., Wilson D.W., MacLachlan N.J., Infection kinetics, prostacyclin release and cytokine-mediated modulation of the mechanism of cell death during bluetongue virus infection of cultured ovine and bovine pulmonary artery and lung microvascular endothelial cells, J. Gen Virol. (2001) 82:787-794.

[19] DeMaula C.D., Leutenegger C.M., Bonneau K.R., MacLachlan N.J., The role of endothelial cell-derived inflammatory and vasoactive mediators in the pathogenesis of bluetongue, Virology (2002) 296:330-337.

[20] Diprose J., Burroughs J.N., Sutton G., Goldsmith A., Gouet P., Malby R., et al., Translocation portals for the substrates and products of a viral transcriptase complex: the Bluetongue virus core, EMBO J. (2001) 20:7229-7239.

[21] Eksteen P.A., Huismans H., Interferon induction by bluetongue virus and bluetongue virus ribonucleic acid, Onderstepoort J. Vet. Res. (1972) 39 $125-131$.

[22] Elbers A.R., Backx A., Ekker H.M., van der Spek A.N., van Rijn P.A., Performance of clinical signs to detect bluetongue virus serotype 8 outbreaks in cattle and sheep during the 2006-epidemic in The Netherlands, Vet. Microbiol. (2008) 129: 156-162.

[23] Ellis J.A., Luedke A.J., Davis W.C., Wechsler S.J., Mecham J.O., Pratt D.L., Elliott J.D., T lymphocyte subset alterations following bluetongue virus infection in sheep and cattle, Vet. Immunol. Immunopathol. (1990) 24:49-67.

[24] Enserink M., Animal disease. Exotic disease of farm animal tests Europe's responses, Science (2008) 319:710-711

[25] Forzan M., Wirblich C., Roy P., A capsid protein of nonenveloped bluetongue virus exhibits membrane fusion activity, Proc. Natl. Acad. Sci. USA (2004) 101:2100-2105.

[26] Forzan M., Marsh M., Roy P., Bluetongue virus entry into cells, J. Virol. (2007) 81:4819-4827.

[27] Foster N.M., Luedke A.J., Parsonson I.M., Walton T.E., Temporal relationships of viremia, interferon activity, and antibody responses of sheep infected with several bluetongue virus strains, Am. J. Vet. Res. (1991) 52:192-196

[28] Fulton R.W., Pearson N.J., Interferon induction in bovine and feline monolayer cultures by four bluetongue virus serotypes, Can. J. Comp. Med. (1982) 46:100-102.

[29] Ghosh M.K., Borca M.V., Roy P., Virus-derived tubular structure displaying foreign sequences on the surface elicit $\mathrm{CD}^{+}$Th cell and protective humoral responses, Virology (2002) 302:383-392.

[30] Gould A.R., Hyatt A.D., The orbivirus genus. Diversity, structure, replication and phylogenetic relationships, Comp. Immunol. Microbiol. Infect. Dis. (1994) 17:163-188.

[31] Grimes J.M., Burroughs J.N., Gouet P., Diprose J.M., Malby R., Ziéntara S., et al., The atomic structure of the bluetongue virus core, Nature (1998) 395:470478 .

[32] Guirakhoo F., Catalan J.A., Monath T.P., Adaptation of bluetongue virus in mosquito cells results in overexpression of NS3 proteins and release of virus particles, Arch. Virol. (1995) 140:967-974.

[33] Han Z., Harty R.N., The NS3 protein of bluetongue virus exhibits viroporin-like properties, J. Biol. Chem. (2004) 279:43092-43097.

[34] Hassan S.H., Wirblich C., Forzan M., Roy P., Expression and functional characterization of bluetongue virus VP5 protein: role in cellular permeabilization, J. Virol. (2001) 75:8356-8367.

[35] Hassan S.S., Roy P., Expression and functional characterization of bluetongue virus VP2 protein: role in cell entry, J. Virol. (1999) 73:9832-9842.

[36] Hervas-Stubbs S., Rueda P., Lopez L., Leclerc C., Insect baculoviruses strongly potentiate adaptive immune responses by inducing type I IFN, J. Immunol. (2007) 178:2361-2369.

[37] Horscroft N.J., Roy P., NTP binding and phosphohydrolase activity associated with purified bluetongue virus non-structural protein NS2, J. Gen. Virol. (2000) 81:1961-1965.

[38] Huismans H., Bluetongue virus-induced interferon synthesis, Onderstepoort J. Vet. Res. (1969) 36:181-185.

[39] Huismans H., Erasmus B.J., Identification of the serotype-specific and group-specific antigens of bluetongue virus, Onderstepoort J. Vet. Res. (1981) 48:51-58.

[40] Huismans H., van der Walt N.T., Cloete M., Erasmus B.J., Isolation of a capsid protein of bluetongue virus that induces a protective immune response in sheep, Virology (1987) 157:172-179.

[41] Huismans H., Van Dijk A.A., Bluetongue virus structural components, Curr. Top. Microbiol. Immunol. (1990) 162:21-41.

[42] Jameson P., Grossberg S.E., Production of interferon in human cell cultures by a new, potent viral inducer, Adv. Exp. Med. Biol. (1978) 110:37-53.

[43] Jameson P., Schoenherr C.K., Grossberg S.E., Bluetongue virus, an exceptionally potent interferon 
inducer in mice, Infect. Immun. (1978) 20:321323.

[44] Janardhana V., Andrew M.E., Lobato Z.I., Coupar B.E., The ovine cytotoxic T lymphocyte responses to bluetongue virus, Res. Vet. Sci. (1999) 67:213221.

[45] Jeggo M.H., Wardley R.C., Generation of cross-reactive cytotoxic $\mathrm{T}$ lymphocytes following immunization of mice with various bluetongue virus types, Immunology (1982) 45:629-635.

[46] Jeggo M.H., Gumm I.D., Taylor W.P., Clinical and serological response of sheep to serial challenge with different bluetongue virus types, Res. Vet. Sci. (1983) 34:205-211.

[47] Jeggo M.H., Wardley R.C., Taylor W.P., Host response to bluetongue virus, In: Compans R.W., Bishop D.H.L. (Eds.), Double-stranded RNA Viruses, Elsevier, New York, USA, 1983, pp. 353-359.

[48] Jeggo M.H., Wardley R.C., Taylor W.P., Role of neutralising antibody in passive immunity to bluetongue infection, Res. Vet. Sci. (1984) 36:81-86.

[49] Jeggo M.H., Wardley R.C., Brownlie J., Importance of ovine cytotoxic $\mathrm{T}$ cells in protection against blue tongue virus infection, In: Barber T.L., Jochim M.M. (Eds.), Bluetongue and related orbiviruses, New York, Alan R. Liss, 1985, pp. 447-487.

[50] Johnson D.J., Ostlund E.N., Stallknecht D.E., Goekjian V.H., Jenkins-Moore M., Harris S.C., First report of bluetongue virus serotype 1 isolated from a white-tailed deer in the United States, J. Vet. Diagn. Invest. (2006) 18:398-401.

[51] Jones L.D., Chuma T., Hails R., Williams T., Roy P., The non-structural proteins of bluetongue virus are a dominant source of cytotoxic $\mathrm{T}$ cell peptide determinants, J. Gen. Virol. (1996) 77:997-1003.

[52] Jones L.D., Williams T., Bishop D., Roy P., Baculovirus-expressed nonstructural protein NS2 of bluetongue virus induces a cytotoxic T-cell response in mice which affords partial protection, Clin. Diagn. Lab. Immunol. (1997) 4:297-301.

[53] Kar A.K., Bhattacharya B., Roy P., Bluetongue virus RNA binding protein NS2 is a modulator of viral replication and assembly, BMC Mol. Biol. (2007) 8:4.

[54] Katz J., Alstad D., Gustafson G., Evermann J., Diagnostic analysis of the prolonged bluetongue virus RNA presence found in the blood of naturally infected cattle and experimentally infected sheep, J. Vet. Diagn. Invest. (1994) 6:139-142.

[55] Larke N., Murphy A., Wirblich C., Teoh D., Estcourt M.J., McMichael A.J., et al., Induction of human immunodeficiency virus type 1 -specific $\mathrm{T}$ cells by a bluetongue virus tubule-vectored vaccine primerecombinant modified virus Ankara boost regimen, J. Virol. (2005) 79:14822-14833.

[56] Lobato Z.I., Coupar B.E., Gray C.P., Lunt R., Andrew M.E., Antibody responses and protective immunity to recombinant vaccinia virusexpressed bluetongue virus antigens, Vet. Immunol. Immunopathol. (1997) 59:293-309.

[57] Lunt R.A., Melville L., Hunt N., Davis S., Rootes C.L., Newberry K.M., et al., Cultured skin fibroblast cells derived from bluetongue virus-inoculated sheep and field-infected cattle are not a source of late and protracted recoverable virus, J. Gen. Virol. (2006) 87:3661-3666.

[58] Maan S., Maan N.S., Samuel A.R., Rao S., Attoui H., Mertens P.P., Analysis and phylogenetic comparisons of full-length VP2 genes of the 24 bluetongue virus serotypes, J. Gen. Virol. (2007) $88: 621-630$

[59] MacLachlan N.J., Thompson J., Bluetongue virus-induced interferon in cattle, Am. J. Vet. Res. (1985) 46:1238-1241.

[60] MacLachlan N.J., Nunamaker R.A., Katz J.B., Sawyer M.M., Akita G.Y., Osburn B.I., Tabachnick W.J., Detection of bluetongue virus in the blood of inoculated calves: comparison of virus isolation, PCR assay, and in vitro feeding of Culicoides variipennis, Arch. Virol. (1994) 136:1-8.

[61] Mellor P.S., The replication of bluetongue virus in Culicoides vectors, Curr. Top. Microbiol. Immunol. (1990) 162:143-161.

[62] Mellor P.S., Boorman J., The transmission and geographical spread of African horse sickness and bluetongue viruses, Ann. Trop. Med. Parasitol. (1995) 89:1-15.

[63] Mellor P.S., Wittmann E.J., Bluetongue virus in the Mediterranean Basin 1998-2001, Vet. J. (2002) 164:20-37.

[64] Mertens P.P., Sangar D.V., Analysis of the terminal sequences of the genome segments of four orbiviruses, Virology (1985) 140:55-67.

[65] Mertens P.P., Burroughs J.N., Anderson J., Purification and properties of virus particles, infectious subviral particles, and cores of bluetongue virus serotypes 1 and 4, Virology (1987) 157:375-386.

[66] Mertens P.P., Pedley S., Cowley J., Burroughs J.N., Corteyn A.H., Jeggo M.H., et al., Analysis of the roles of bluetongue virus outer capsid proteins VP2 and VP5 in determination of virus serotype, Virology (1989) 170:561-565.

[67] Mertens P.P., Burroughs J.N., Walton A., Wellby M.P., Fu H., O'Hara R.S., et al., Enhanced infectivity of modified bluetongue virus particles for two insect

Page 14 of 16 (page number not for citation purpose) 
cell lines and for two Culicoides vector species, Virology (1996) 217:582-593.

[68] Mertens P.P., Diprose J., The bluetongue virus core: a nano-scale transcription machine, Virus Res. (2004) 101:29-43.

[69] Mertens P.P., Maan N.S., Prasad G., Samuel A.R., Shaw A.E., Potgieter A.C., et al., Design of primers and use of RT-PCR assays for typing European bluetongue virus isolates: differentiation of field and vaccine strains, J. Gen. Virol. (2007) 88:2811-2823.

[70] Mertens P.P.C., Maan S., Samuel A., Attoui H., Orbivirus, Reoviridae, In: Fauquet C.M., Mayo M.A., Maniloff J., Desselberger U., Ball L.A (Eds.), Virus taxonomy, VIIIth report of the ICTV, Elsevier/Academic press, London, UK, 2004 pp. $466-483$.

[71] Meyrick B., Hoover R., Jones M.R., Berry L.C. Jr., Brigham K.L., In vitro effects of endotoxin on bovine and sheep lung microvascular and pulmonary artery endothelial cells, J. Cell. Physiol. (1989) 138:165-174.

[72] Monath T.P., Guirakhoo F., Orbivurses and Coltiviruses, In: Fields B.N., Knipe D.M., Howley P.M. (Eds.), Virology, Lippincott, Raven, Boston, Massachusetts, USA, 1996, pp. 1735-1766.

[73] Mortola E., Noad R., Roy P., Bluetongue virus outer capsid proteins are sufficient to trigger apoptosis in mammalian cells, J. Virol. (2004) 78:2875-2883.

[74] Nason E.L., Rothagel R., Mukherjee S.K., Kar A.K., Forzan M., Prasad B.V., Roy P., Interactions between the inner and outer capsids of bluetongue virus, J. Virol. (2004) 78:8059-8067.

[75] Owens R.J., Limn C., Roy P., Role of an arbovirus nonstructural protein in cellular pathogenesis and virus release, J. Virol. (2004) 78:6649-6656.

[76] Parsonson I., Overview of bluetongue virus infection in sheep, In: Walton T., Osburn B. (Eds.), Bluetongue, African horsesickness, and related orbiviruses, CRC Press, Boca Raton, FL, USA, 1992, pp. 713-724.

[77] Parsonson I.M., Pathology and pathogenesis of bluetongue infections, Curr. Top. Microbiol. Immunol. (1990) 162:119-141.

[78] Perrin A., Albina E., Bréard E., Sailleau C., Promé S., Grillet C., et al., Recombinant capripoxviruses expressing proteins of bluetongue virus: evaluation of immune responses and protection in small ruminants, Vaccine (2007) 25:6774-6783.

[79] Purse B.V., Mellor P.S., Rogers D.J., Samue A.R., Mertens P.P., Baylis M., Climate change and the recent emergence of bluetongue in Europe, Nat. Rev. Microbiol. (2005) 3:171-181.
[80] Rinaldo C.R. Jr., Overall J.C. Jr., Glasgow L.A., Viral replication and interferon production in fetal and adult ovine leukocytes and spleen cells, Infect. Immun. (1975) 12:1070-1077.

[81] Roy P., Urakawa T., Van Dijk A.A., Erasmus B.J., Recombinant virus vaccine for bluetongue disease in sheep, J. Virol. (1990) 64:1998-2003.

[82] Roy P., Bluetongue virus proteins, J. Gen. Virol. (1992) 73:3051-3064.

[83] Roy P., French T., Erasmus B.J., Protective efficacy of virus-like particles for bluetongue disease, Vaccine (1992) 10:28-32.

[84] Roy P., Bishop D.H., LeBlois H., Erasmus B.J., Long-lasting protection of sheep against bluetongue challenge after vaccination with virus-like particles: evidence for homologous and partial heterologous protection, Vaccine (1994) 12:805-811.

[85] Saegerman C., Berkvens D., Mellor P.S., Bluetongue Epidemiology in the European Union, Emerging Infect. Dis. (2008) 14:539-544.

[86] Savini G., Maclachlan N.J., Sanchez-Vizcaino J.M., Zientara S., Vaccines against bluetongue in Europe, Comp. Immunol. Microbiol. Infect. Dis. (2008) 31:101-120.

[87] Shad G., Wilson W.C., Mecham J.O., Evermann J.F., Bluetongue virus detection: a safer reversetranscriptase polymerase chain reaction for prediction of viremia in sheep, J. Vet. Diagn. Invest. (1997) 9:118-124.

[88] Singh K.P., Maan S., Samuel A.R., Rao S., Meyer A., Mertens P.P., Phylogenetic analysis of bluetongue virus genome segment 6 (encoding VP5) from different serotypes, Vet. Ital. (2005) 40: 479-483.

[89] Stäuber N., Martinez-Costas J., Sutton G., Monastyrskaya K., Roy P., Bluetongue virus VP6 protein binds ATP and exhibits an RNA-dependent ATPase function and a helicase activity that catalyze the unwinding of double-stranded RNA substrates, J. Virol. (1997) 71:7220-7226.

[90] Stott J.L., Osburn B.I., Barber T.L., Sawyer M.M., Immunological response of sheep to an experimental inactivated BTV vaccine, J. Am. Vet. Med. Assoc. (1979) 175:611-615.

[91] Stuart D.I., Gouet P., Grimes J., Malby R., Diprose J., Zientara S., et al., Structural studies of orbivirus particles, Arch. Virol. Suppl. (1998) 14: 235-250.

[92] Sutton G., Grimes J.M., Stuart D.I., Roy P., Bluetongue virus VP4 is an RNA-capping assembly line, Nat. Struct. Mol. Biol. (2007) 14: 449-451. 
[93] Tabachnick W.J., Culicoides variipennis and bluetongue-virus epidemiology in the United States, Annu. Rev. Entomol. (1996) 41:23-43.

[94] Takamatsu H., Jeggo M.H., Cultivation of bluetongue virus-specific ovine $\mathrm{T}$ cells and their crossreactivity with different serotype viruses, Immunology (1989) 66:258-263.

[95] Takamatsu H., Burroughs J.N., Wade-Evans A.M., Mertens P.P., Analysis of bluetongue virus serotype-specific and cross reactive ovine T-cell determinants in virus structural proteins, In: Walton T.E., Osburn B.I. (Eds.), Bluetongue, African horse sickness and related orbiviruses, CRC Press, Boca Raton, FL, USA, 1992, pp. 491-497.

[96] Takamatsu H., Mellor P.S., Mertens P.P., Kirkham P.A., Burroughs J.N., Parkhouse R.M., A possible overwintering mechanism for bluetongue virus in the absence of the insect vector, J. Gen. Virol. (2003) 84:227-235.

[97] Tan B.H., Nason E., Staeuber N., Jiang W., Monastryrskaya K., Roy P., RGD tripeptide of bluetongue virus VP7 protein is responsible for core attachment to Culicoides cells, J. Virol. (2001) 75:3937-3947.

[98] Veronesi E., Hamblin C., Mellor P.S., Live attenuated bluetongue vaccine viruses in Dorset Poll sheep, before and after passage in vector midges (Diptera: Ceratopogonidae), Vaccine (2005) 23:55095516.

[99] Wade-Evans A.M., Romero C.H., Mellor P., Takamatsu H., Anderson J., Thevasagayam J., et al.,
Expression of the major core structural protein (VP7) of bluetongue virus, by a recombinant capripox virus, provides partial protection of sheep against a virulent heterotypic bluetongue virus challenge, Virology (1996) 220:227-231.

[100] Whetter L.E., Maclachlan N.J., Gebhard D.H., Heidner H.W., Moore P.F., Bluetongue virus infection of bovine monocytes, J. Gen. Virol. (1989) 70:16631676.

[101] White D.M., Wilson W.C., Blair C.D., Beaty B.J., Studies on overwintering of bluetongue viruses in insects, J. Gen. Virol. (2005) 86:453-462.

[102] Wilson D.C., Ma H.C., Venter E.H., van Djik A.A., Seal B.S., Mecham J.O., Phylogenetic relationships of bluetongue viruses based on gene S7, Virus Res. (2000) 67:141-151.

[103] Wilson W.C., Bernard K.A., Israel B.A., Mecham J.O., Bluetongue virus serotype 17 sequence variation associated with neutralization, DNA Seq. (2008) 237-240.

[104] Wirblich C., Bhattacharya B., Roy P., Nonstructural protein 3 of bluetongue virus assists virus release by recruiting ESCRT-I protein Tsg101, J. Virol. (2006) 80:460-473.

[105] Zhao Y., Thomas C., Bremer C., Roy P., Deletion and mutational analyses of bluetongue virus NS2 protein indicate that the amino but not the carboxy terminus of the protein is critical for RNA-protein interactions, J. Virol. (1994) 68:21792185. 